\title{
SEed-Mass efFects in four Mediterranean QuerCuS SPECIES (FAGACEAE) GROWING IN CONTRASTING LIGHT ENVIRONMENTS ${ }^{1}$
}

\author{
José Luis Quero, ${ }^{2,3,5,6}$ Rafael Villar, ${ }^{3}$ Teodoro Marañón, ${ }^{4}$ Regino Zamora, ${ }^{2}$ and Lourens Poorter ${ }^{5}$
}

\author{
${ }^{2}$ Grupo de Ecología Terrestre, Departamento de Ecología, Facultad de Ciencias, Universidad de Granada, 18071 Granada, Spain; \\ ${ }^{3}$ Área de Ecología, Facultad de Ciencias, Universidad de Córdoba, 14071 Córdoba, Spain; ${ }^{4}$ Instituto de Recursos Naturales y \\ Agrobiología, CSIC, P.O. Box 1052, 41080 Seville, Spain; and ${ }^{5}$ Forest Ecology and Forest Management Group, Centre for \\ Ecosystem Studies, Wageningen University, P.O. Box 47, 6700 AA Wageningen, The Netherlands
}

\begin{abstract}
Three hypotheses have been proposed to explain the functional relationship between seed mass and seedling performance: the reserve effect (larger seeds retain a larger proportion of reserves after germinating), the metabolic effect (seedlings from larger seeds have slower relative growth rates), and the seedling-size effect (larger seeds produce larger seedlings). We tested these hypotheses by growing four Mediterranean Quercus species under different light conditions (3, 27, and 100\% of available radiation). We found evidence for two of the three hypotheses, but none of the four species complied with all three hypotheses at the same time. The reserve effect was not found in any species, the metabolic effect was found in three species $(Q$. ilex, $Q$. pyrenaica, and $Q$. suber), and the seedling-size effect in all species. Light availability significantly affected the relationships between seed size and seedling traits. For $Q$. ilex and $Q$. canariensis, a seedling-size effect was found under all three light conditions, but only under the lowest light (3\%) for $Q$. suber and Q. pyrenaica. In all species, the correlation between seed mass and seedling mass increased with a decrease in light, suggesting that seedlings growing in low light depend more upon their seed reserves. A causal model integrates the three hypotheses, suggesting that larger seeds generally produced larger seedlings.
\end{abstract}

Key words: acorn mass; Fagaceae; light availability; Mediterranean oaks; Quercus; RGR; seed-seedling relationships; seed size.

Seed mass represents the amount of reserves an embryo contains to start its first life stages. For the mother plant, there is a trade-off between producing many small seeds vs. fewer larger seeds from a given quantity of resource allocated to reproduction. Despite selection pressure to produce more seeds and more offspring, larger offspring have a greater chance of establishing (Leishman et al., 2000). Thus, seed size is one of the most important traits influencing the early phases of the plant's life cycle, including germination (Milberg et al., 2000; Pearson et al., 2002), emergence (Castro, 1999), growth, and survival of seedlings (Seiwa, 2000; Baraloto et al., 2005).

Three mechanisms have been proposed to explain functional seed-seedling relationships (Westoby et al., 1996; Leishman et al., 2000). (1) The reserve effect predicts that, after germination, larger seeds retain a greater proportion of their seed reserves, which can then be mobilized for seedling growth, maintenance, and repair. Thus, the extra reserves in the

\footnotetext{
${ }^{1}$ Manuscript received 22 November 2006; revision accepted 6 September 2007.

The authors thank the glasshouse staff of the University of Cordoba for their advice and E. Retamosa, M. Gómez, A. Murillo, M. Ascensión Villar, R. Villar Jr., T. Pérez, and A. Pérez for their help during the experiment. L. Vega helped with the data analysis, and I. M. Pérez-Ramos and Vico González helped with the seed-fruit relationships. F. Valladares advised us about red-far red measurements. J.L.Q. wishes to thank the Forest Ecology and Forest Management group of Wageningen University for hosting him during the writing of this paper (Estancia Breve 2006 fellowship, MEC). D. Nesbitt reviewed the English version of the manuscript. This study was supported by the grant FPI-MEC to J.L.Q. (BES-2003-1716) and by the coordinated Spanish MEC projects HETEROMED (REN2002-04041) and DINAMED (CGL2005-05830). This research is part of the REDBOME and GLOBIMED networks on forest ecology.

${ }^{6}$ Author for correspondence (e-mail: jlquero@ugr.es), phone: + 34 958243242 , fax: + 34958243238
}

large cotyledons improve the chances that the seedling can establish when environmental conditions are adverse (GarcíaCebrián et al., 2003; Green and Juniper, 2004a). (2) The metabolic effect predicts a negative relationship between seed size and relative growth rate (RGR) during the early stages (Cornelissen et al., 1996; Saverimuttu and Westoby, 1996; Wright and Westoby, 1999). A higher specific leaf area (SLA, leaf area/leaf dry mass), lower DNA content, and smaller cell size are thought to contribute to the growth advantage of smallseeded seedlings (Marañón and Grubb, 1993), whereas in larger-seeded seedlings the growth disadvantage is compensated by higher initial plant mass. (3) The seedling-size effect foresees that larger seeds produce larger seedlings, which are more robust and better able to escape size-dependent mortality. In addition to being able to emerge from deeper soil layers (Bond et al., 1999), the larger seedlings have a larger shoot, which can overtop neighboring seedlings and capture more light (Foster, 1986). Larger seedlings also form deeper and more extensive roots, which can capture more soil water during the dry season (Metcalfe and Grubb, 1997; Lloret et al., 1999; Poorter and Hayashida, 2001).

Since the publication of the seminal paper by Westoby et al. (1996), where the three seed-size hypotheses were presented, most studies have analyzed the effect of seed size on seedling performance by comparing different species with contrasting life-history traits (Saverimuttu and Westoby, 1996; Poorter and Rose, 2005). In these types of studies, the main objective is to explain the seed-seedling relationship from an evolutionary standpoint (Wright et al., 2000; Westoby et al., 2002). However, species vary not only in their seed size but also in many other traits, potentially leading to confusion about functional effects of seed size with correlated variation due to life history. For instance, small-seeded species tend to be lightdemanding and generally have photosynthetic-type cotyledons and a high SLA and leaf area ratio (LAR, plant area/plant 
biomass), whereas large-seeded species tend to be shadetolerant and have the opposite suite of traits (Kitajima, 1996; Poorter and Rose, 2005; Zanne et al., 2005). A within-species analysis may therefore more clearly show the functional significance of seed size, although few studies have taken such an approach (but see Ke and Werger, 1999; Green and Juniper, 2004a).

Seed-size variation is thought to be important for the establishment of seedlings under different ecological conditions. Species with considerable intraspecific variation in seed size may therefore enhance their establishment in a heterogeneous environment. This might apply to Quercus species, which have considerable interspecific (Aizen and Patterson, 1990) and intraspecific (Leiva and Fernandez-Alés, 1998) variation in seed size.

The effect of seed size on seedling performance is highly variable and depends on environmental conditions such as light availability (Leishman and Westoby, 1994; Rose, 2000; Poorter and Rose, 2005), nutrient availability (Jurado and Westoby, 1992), and damage by herbivores (Harms and Dalling, 1997). For instance, Rose (2000) found that seedling survival for eight rainforest tree species was closely and positively correlated with seed size in low irradiance; in high irradiance, however, the relationship between seedling survival and seed size was weak or insignificant.

Light availability at the forest floor is very heterogeneous in space and time (Valladares, 2001), and many studies have demonstrated its importance for the regeneration of Mediterranean woody species (Sack, 2004; Gómez-Aparicio et al., 2006). We predict that Quercus seedlings growing in deep shade and with reduced carbon gain (Quero et al., 2006) will depend more strongly on their acorn reserves than will seedlings growing under higher light levels.

The objective of this study is to evaluate the functional importance of seed size within four Mediterranean Quercus species. Specifically, four questions were asked. (1) Do larger seeds retain proportionally more reserves, which may be advantageous for overcoming potential hazards (the reserve effect)? (2) Is seed mass negatively related to seedling RGR (the metabolic effect)? (3) Do larger seeds result in a larger initial seedling biomass (the seedling size effect)? (4) Do these relationships change with light availability?

The three hypotheses have been postulated as mechanisms that explain how seedlings survive different environmental hazards (Westoby et al., 1996). Here we present a conceptual framework that connects the three hypotheses.

\section{MATERIALS AND METHODS}

Experimental design - Four oak species typical of Mediterranean forests in southern Spain were selected (Table 1): two evergreen species [Quercus suber L. and $Q$. ilex subsp. ballota (Desf.) Samp.] and two deciduous species $(Q$. canariensis Willd. and $Q$. pyrenaica Willd.). Because all four species have storage-type cotyledons, we avoided the problem of comparing species with different types of cotyledons (Kitajima, 1996; Green and Juniper, 2004a). Seeds were collected during autumn 2002 in southern Spain (Table 1) and stored on a moist substrate at $5^{\circ} \mathrm{C}$ until sown. Single acorns were weighed individually before sowing to determine their fresh mass. A subsample of each species was oven-dried at $70^{\circ} \mathrm{C}$ for at least $48 \mathrm{~h}$ and weighed to determine dry mass. The seeds of the dry acorns were separated from the pericarp and weighed. Speciesspecific regression equations were made for (1) acorn dry mass vs. acorn fresh mass and (2) seed dry mass vs. acorn dry mass. These regressions were used to estimate for each individual the seed dry mass from the acorn fresh mass (Table 1). The experiment was carried out in a glasshouse of the University of
Cordoba, Spain (at $37^{\circ} 51^{\prime} \mathrm{N}, 4^{\circ} 48^{\prime} \mathrm{W}$, and $100 \mathrm{~m}$. a.s.1.). In December 2002 , acorns were separately sown in cylindrical pots $(50 \mathrm{~cm}$ height, $10.5 \mathrm{~cm}$ diameter, $3.9 \mathrm{~L}$ volume). A large pot was used to allow for extensive root growth. Pots contained a mixture $(2: 1)$ of sand and peat. The air temperature was maintained between 15 and $25^{\circ} \mathrm{C}$.

Seedlings were subjected to three light levels or treatments: a highirradiance (HI), a medium-irradiance (MI), or a low-irradiance (LI) treatment, corresponding to $100 \%, 27 \%$, or $3 \%$ of the available radiation in the greenhouse. Each light treatment was replicated four times. Light was reduced with a dense green cloth in the LI treatment, a light screen in the MI treatment and no screen or cloth was used for the HI treatment. The screen or cloth was attached to a "shade frame" $(150 \times 120 \times 200 \mathrm{~cm})$. The mean $\pm \mathrm{SE}$ of the photosynthetic active radiation measured around noon every day in January 2003 was $281 \pm 28(\mathrm{HI}), 76 \pm 9(\mathrm{MI})$, and $9 \pm 1$ (LI) $\mu \mathrm{mol}$ of photons $\cdot \mathrm{m}^{-2} \cdot \mathrm{s}^{-1}$. These are typical light levels in large forest clearings (HI), below individual trees (MI), and under deep shade of the forest understorey (LI) (Marañón et al., 2004). Light quality, red : far-red ratio (R : FR ratio), was measured with a light sensor (SKR 110, Skye Instruments, Llandrindod Wells, $\mathrm{UK})$. In the LI treatment, the $\mathrm{R}: \mathrm{FR}$ ratio was $0.25 \pm 0.004$, which is comparable to the $\mathrm{R}:$ FR in dense forest microhabitats $\left(0.28 \pm 0.03, t\right.$-test $t_{36}$ $=1.02, P=0.31$ ), while in the other two treatments ( $\mathrm{HI}$ and $\mathrm{MI})$, the $\mathrm{R}: \mathrm{FR}$ was $1.00 \pm 0.03$, which is similar to the ratio in open areas and below trees.

Once the seedlings emerged (the date was recorded for each seedling), the pots were drip irrigated to ensure that water was not limiting. After ca. $50 \mathrm{~d}$ (mean 51, range 48-55) of growth, at least 15 seedlings of each species per light treatment were harvested. We harvested after $50 \mathrm{~d}$ because field studies have shown that seedlings complete their spring growth within $50 \mathrm{~d}$ (Quero et al., 2003). Individual seedlings were carefully removed from each pot, and the soil was gently washed from the roots. Plants were separated into acorn remnant, leaves, stem, and roots. Dry mass of the plant organs was determined after oven-drying at $70^{\circ} \mathrm{C}$ for at least $48 \mathrm{~h}$. The acorn was separated into the pericarp, and the remaining seed was weighed. The used seed reserve was calculated as the difference between the estimated initial seed dry mass and the remnant seed dry mass at harvest. The relative growth rate (RGR, rate of biomass increase per unit of plant biomass) was calculated as the natural log of seedling biomass minus the natural log of used seed reserve (Steege et al., 1994) divided by the growth period.

Statistical analysis - A two-way ANOVA was used to evaluate differences in seed mass among four species and three light treatments, and a post-hoc test (Tukey's honestly significant difference test for unequal $N$ ) was used to evaluate how initial seed mass varied with light treatment for each species. Data were arcsine or $\log$ transformed before analysis to meet the assumptions of normality and homoscedasticity (Zar, 1984). The program STATISTICA $\vee 6.0$ (Statsoft, Tulsa, Oklahoma, USA) was used for statistical analyses.

Within each species, we explored the relationship between seeds and seedlings among light treatments using standard major axis (SMA) regressions (Legendre, 2000). Our goal was to calculate the intraspecific allometric slopes and their 95\% confidence limits to compare data within the three light treatments and to determine whether these slopes were consistent with the hypotheses against a null model of slope 1 or 0 , as discussed next.

If the reserve effect (larger seeds retain a greater proportion of reserves after germination) is true, then two conditions should be met (the following assumes log transformation of all variables other than RGR): (1) the slope of used reserve vs. seed mass should be significantly less than one, and (2) the slope of seedling mass vs. seed mass should be significantly greater than that of the used reserve vs. seed mass. If the second condition is met, it signifies that the retained reserve have improved seedling performance (for more details, see Green and Juniper, 2004a). To support the metabolic effect (larger seeds have slower RGR), the slope of RGR vs. seed mass should be significantly less than zero. To support the seedling-size effect (larger seeds produce larger seedlings), the slope of seedling mass vs. seed mass should be significantly greater than zero. SMA regressions were done for each species and light treatment using the (S)MATR package of Falster et al. (2003). SMA slopes for different light treatments were compared against each other using routines in the (S)MATR package.

A causal model connecting the three hypotheses-The hypothesis of the reserve effect was tested using the relationship between the used reserve and seed mass (Fig. 1A) and can be parameterized as

$\ln ($ used reserve $)=a_{1}+b_{1} \times \ln ($ seed mass $)$, 
TABLE 1. Oak species included in the experiment (nomenclature follows Amaral, 1990); their frequency in southern Spain (Urbieta et al., 2004); origin of seed; regression equations used to calculate initial acorn dry mass $\left(A_{\mathrm{DM}}\right)$ from initial acorn fresh mass $\left(A_{\mathrm{FM}}\right)$, and initial seed dry mass $\left(S_{\mathrm{DM}}\right)$ from initial acorn dry mass $\left(A_{\mathrm{DM}}\right) ; N$ and $R^{2}$ of the regressions; and the mean $( \pm \mathrm{SE})$, range, and coefficient of variation $(\mathrm{CV})$ of initial seed dry mass used in this experiment $(N=47-48$ per species $)$.

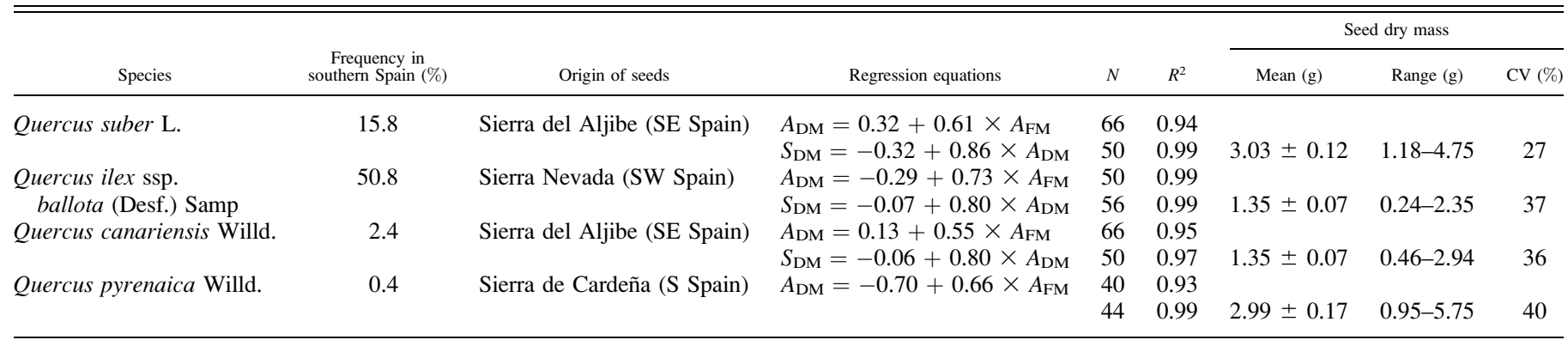
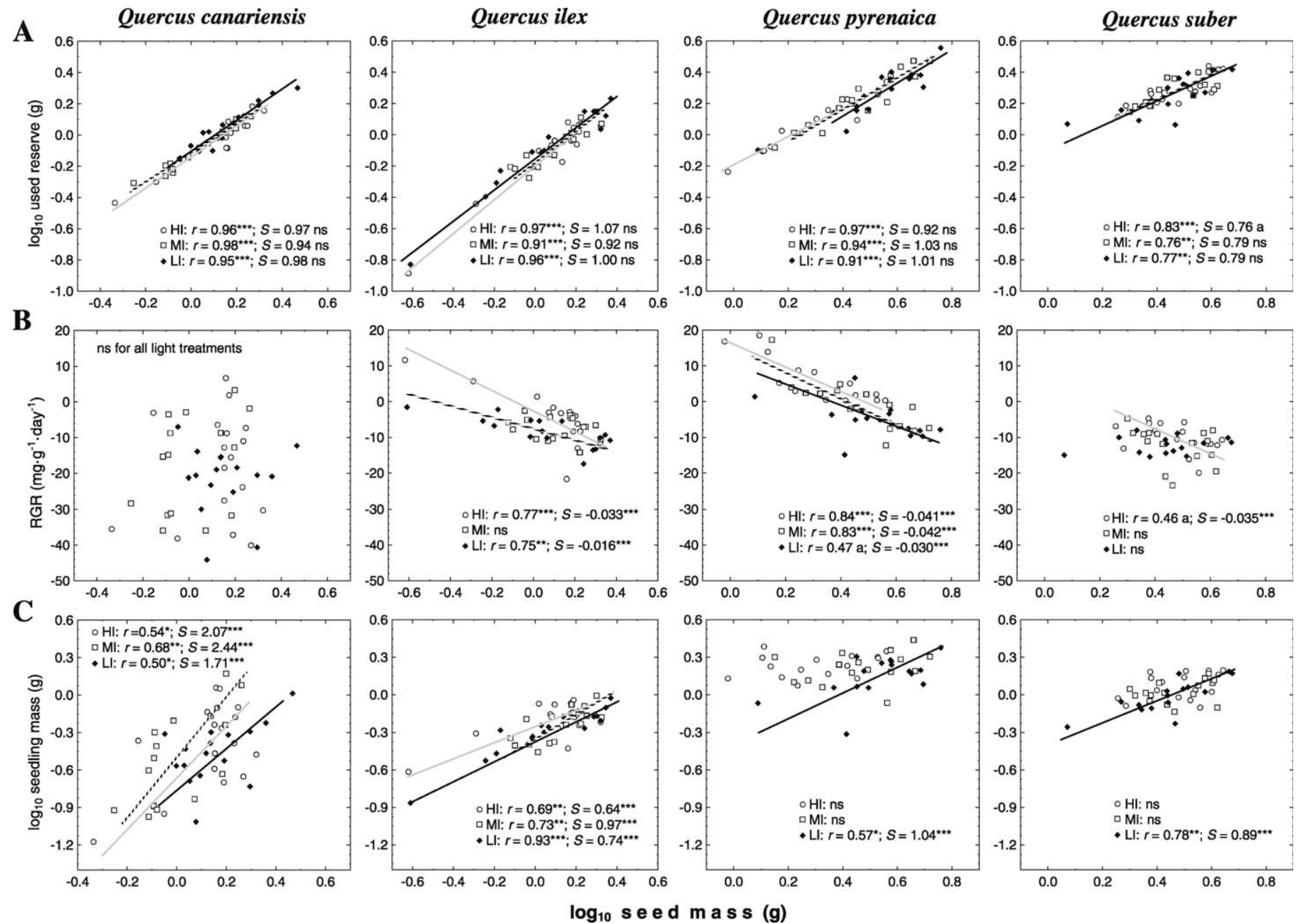

Fig. 1. Used seed reserve, relative growth rate (RGR), and seedling biomass after ca. $50 \mathrm{~d}$ of growth vs. $\log$ initial seed dry mass in four $Q u e r c u s$ species (species are arranged from lowest to highest mean seed mass). Pearson correlation and significance are indicated as: ns, not significant; a, $P<0.1$; $* P<0.05 ; * * P<0.01 ; * * * P<0.001$. The standardized major axis regression (SMA) lines are given when they are significant: gray line for high irradiance (HI), dotted line for medium irradiance (MI), and black line for low irradiance (LI). The slope of each SMA regression $(S)$ and their significance against the null model $(S=1$ for the reserve effect, and $S=0$ for the metabolic effect and the seedling-size effect) is given. 
where $a_{1}$ is the intercept and $b_{1}$ is the slope. If $b_{1}<1$, then condition 1 of the reserve effect hypothesis is accepted.

The hypothesis of the metabolic effect was tested using the relationship between RGR and seed mass (Fig. 1B) and parameterized as

$$
\mathrm{RGR}=a_{2}+b_{2} \times \ln (\text { seed mass }) .
$$

If $b_{2}<0$, then the metabolic-effect hypothesis is accepted.

The hypothesis of seedling-size effect was tested using the relationship between seedling biomass and seed mass and parameterized as

$$
\ln (\text { seedling biomass })=a_{3}+b_{3} \times \ln (\text { seed mass }) .
$$

If $b_{3}>0$, then the hypothesis of seedling-size effect is accepted.

The relative growth rate (RGR) was defined as

$$
\mathrm{RGR}=[\ln (\text { seedling biomass })-\ln (\text { used reserve })] / T,
$$

where $T$ is the time of growth. Rearranging Eq. 4, we have

$$
\ln (\text { seedling biomass })=\ln (\text { used reserve })+(\operatorname{RGR} \times T) .
$$

In Eq. 5, if we replace $\ln$ (used reserve) with the equivalent from Eq. 1 and replace RGR with the equivalent in Eq. 2, we have:

$$
\begin{aligned}
\ln (\text { seedling biomass })= & {\left[a_{1}+b_{1} \times \ln (\text { seed mass })\right] } \\
& +\left[a_{2}+b_{2} \times \ln (\text { seed mass })\right] \times T
\end{aligned}
$$

Rearranging the equation:

$\ln ($ seedling biomass $)=\left(a_{1}+a_{2} \times T\right)+\left(b_{1}+b_{2} \times T\right) \times \ln ($ seed mass $),(6)$

which is similar to Eq. 3, where $a_{3}=\left(a_{1}+a_{2} \times T\right)$ and $b_{3}=\left(b_{1}+b_{2} \times T\right)$.

Note that we used natural logarithm instead of $\log _{10}$ in the causal model because RGR was calculated using $\ln$, although the slopes of the relationships based on natural logarithm or $\log _{10}$ are the same.

Because we are interested in the slope of seedling biomass vs. seed mass $\left(b_{3}\right)$, we can state that this slope depends on the slope of used reserve vs. seed mass $\left(b_{1}\right)$ and the slope of RGR vs. seed mass $\left(b_{2}\right)$ and also on the time of growth. Because we are interested in the prediction of $Y$ from given values of $X$, a linear regression is more appropriate than a SMA regression (Falster et al., 2003). Therefore, to connect the three hypotheses, we use the slope calculated from the linear regressions. To test graphically the connection between the three hypotheses, we simulated three data sets for the reserve effect using Eq. 1 $\left(b_{1}>1, b_{1}=1\right.$, and $\left.b_{1}<1\right)$, and we simulated three data sets for the metabolic effect using Eq. $2\left(b_{2}>0, b_{2}=0\right.$, and $\left.b_{2}<0\right)$. Then, we used these data sets to calculate nine data sets resulting from different combinations of $b_{1}$ and $b_{2}$ slopes, and $b_{3}$ slopes were checked according to Eq. 6 . Simulations were made using Excel 2000 (Microsoft, Redmond, Washington, USA).

\section{RESULTS}

Differences in seed mass among Quercus species-Means of the different variables measured in the four Quercus species in the three light treatments are presented in Table 2. Initial seed mass significantly differed among Quercus species (ANOVA $F_{3,179}=68.82, P<0.05$ ). Quercus canariensis and $Q$. ilex had smaller seeds (about $1.5 \mathrm{~g}$ dry mass) whereas $Q$. suber and $Q$. pyrenaica had larger seeds (about $3.0 \mathrm{~g}$ dry mass). Within species, there was a five-fold difference in seed mass (Table 1). There was no bias in assigning different seed masses among light treatments (ANOVA $F_{2,179}=1.03, P=$ 0.36). However, a significant species-light interaction resulted (ANOVA $F_{6,179}=3.35, P<0.05$ ) because smaller acorns of $Q$. pyrenaica were inadvertently selected for the HI treatment (Table 2).

Reserve effect-For all species and light treatments, the seed reserves used for the $50 \mathrm{~d}$ of growth were positively related to the initial seed mass (Fig. 1A). Quercus suber in HI was the only species that met condition 1 of the reserve effect, because

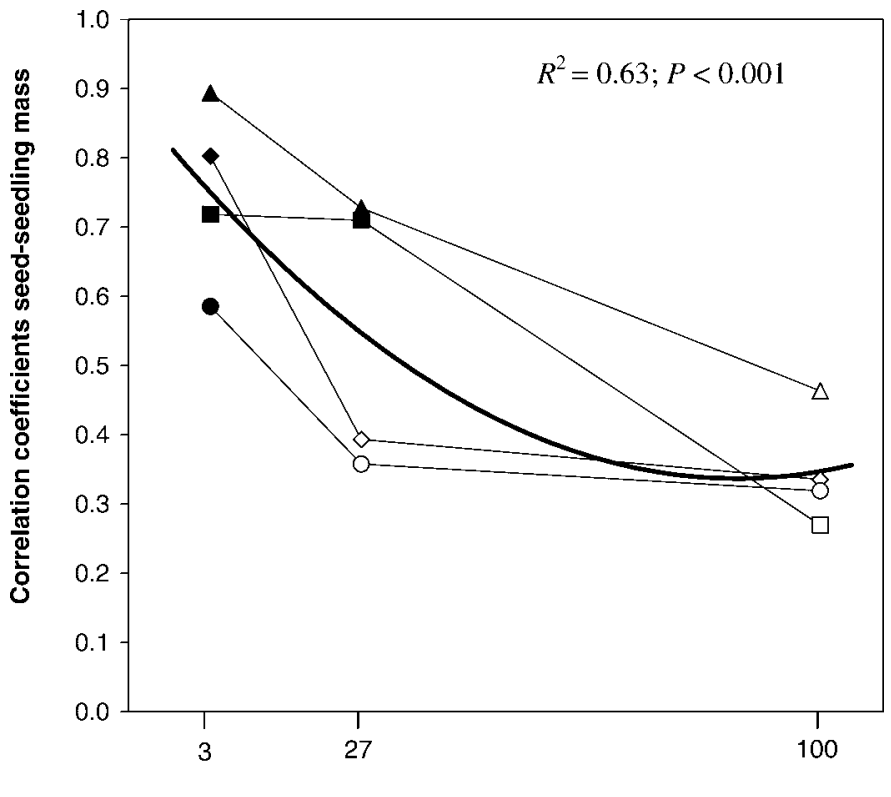

Irradiance (\%)

Fig. 2. Pearson correlation coefficients for seed mass vs. seedling mass after ca. $50 \mathrm{~d}$ of seedling growth for the four oak species under three light conditions $(3,27$, and $100 \%)$. Quercus ilex subsp. ballota $(\Delta), Q$. canariensis $(\square)$, $Q$. suber $(\diamond)$, and $Q$. pyrenaica $(\circ)$. Black symbols indicate significant correlations $(P<0.05)$. Thick line indicates secondorder polynomial regression $\left(y=0.78-0.0102 \times x+5.8 \times 10^{-5} \times x^{2}\right)$.

its use of reserves decreased as seed size increased (the SMA slope was 0.76 , marginally less than 1 with $P=0.09$; Fig. 1A). To fulfill condition 2 of the reserve effect, the slope of the log of seedling mass vs. the log of seed mass should also be significantly greater than that of the log of used reserve vs. the $\log$ of seed mass. For $Q$. suber in HI, condition 2 of the reserve effect was not met because the relationship between seedling mass and seed mass was not significant; hence, the slope was likely to be near zero. For $Q$. suber in MI and LI and for the other species regardless of light treatment, the SMA slope did not differ from 1.

Metabolic effect-For Quercus canariensis, RGR was not related to seed mass for the three light treatments, whereas for $Q$. ilex in $\mathrm{HI}$ and $\mathrm{LI}$, for $Q$. pyrenaica in the three light treatments, and for $Q$. suber in HI, RGR was negatively related to seed mass (supporting the metabolic-effect hypothesis for these light treatments; Fig. 1B). For $Q$. ilex and $Q$. pyrenaica, slopes of RGR vs. seed mass increased with increasing light but only significantly so for $Q$. ilex $[(\mathrm{S}) \mathrm{MATR}$ test statistic $=$ $7.48, P=0.027$; Fig. 1B].

Seedling-size effect-After $50 \mathrm{~d}$ of growth, seedling biomass was positively related to seed mass for all species (Fig. 1C), in agreement with the seedling-size effect, although the effect depended on light availability. For Quercus ilex and $Q$. canariensis, seedling mass was positively related to seed mass for the three light treatments (Fig. 1C) and the slopes for light treatments were similar $((\mathrm{S}) \mathrm{MATR}$ test statistic $=2.46, P$ $=0.31$ for $Q$. ilex; (S)MATR test statistic $=1.27, P=0.52$ for $Q$. canariensis). For Quercus suber and $Q$. pyrenaica, 


\section{Reserve effect}

A
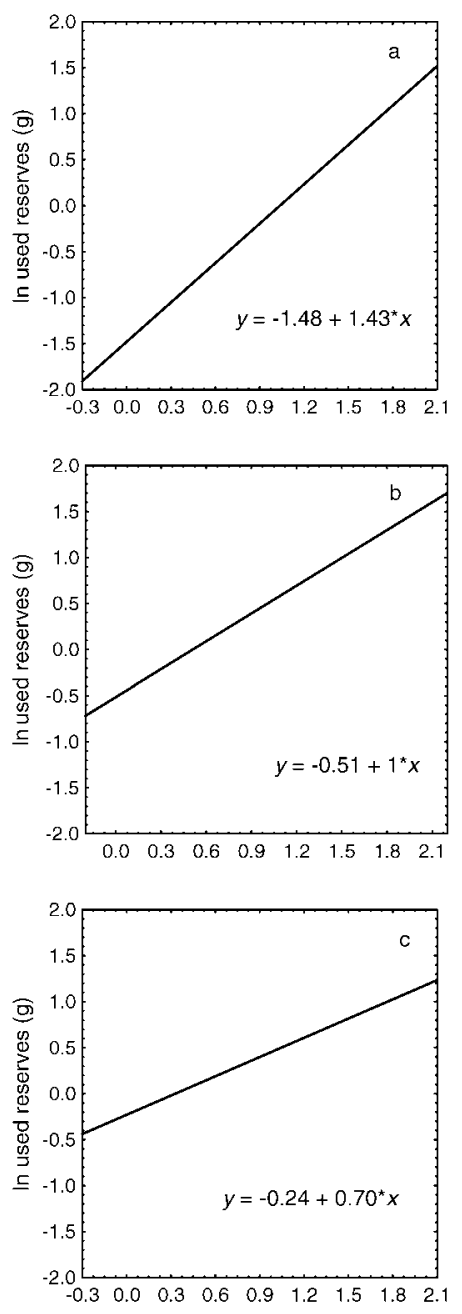

Metabolic effect

\section{B}
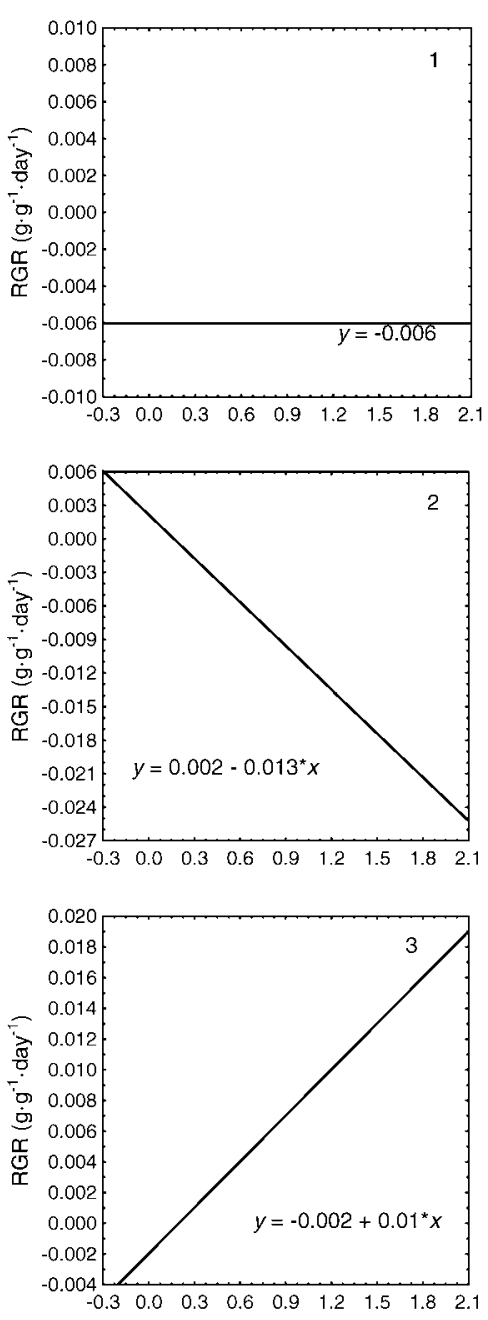

Seedling-size effect
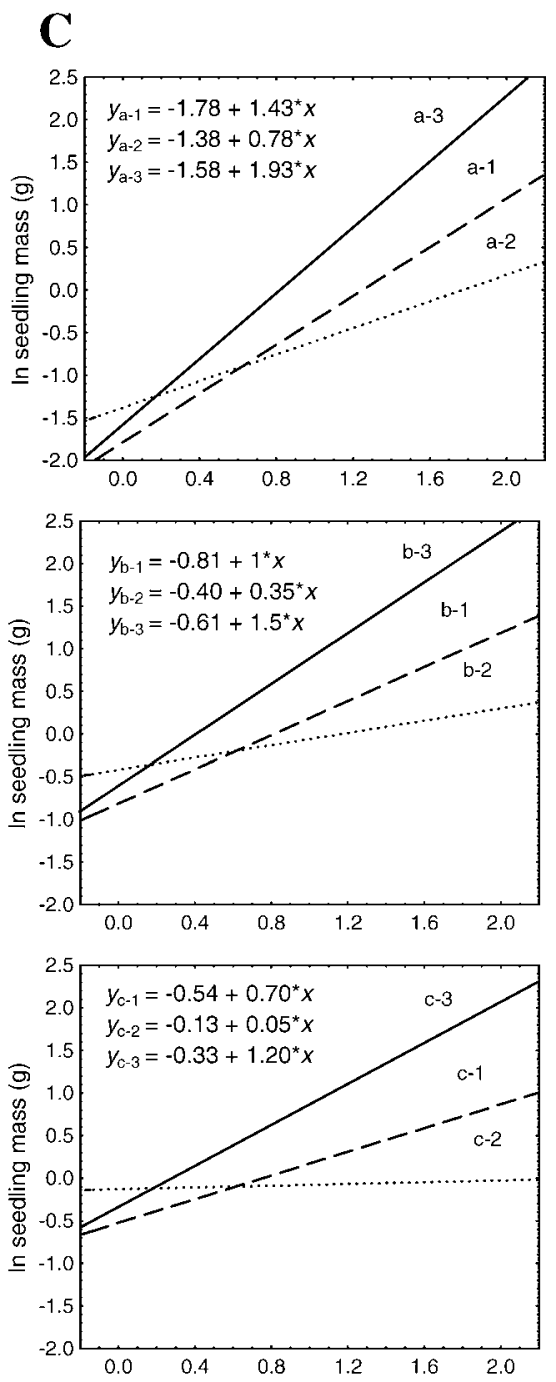

In seed mass (g)

Fig. 3. Simulations of the causal model. (A) a, b, and c represent possible contrasting results of the relationship of used seed reserve vs. seed mass (the reserve effect). (B) 1, 2, and 3 represent possible contrasting results of the relationship relative growth rate (RGR) vs. seed mass (the metabolic effect). (C) The results of the seedling biomass-seed mass relationship (seedling-size effect) depending on the combinations of a, b, and c with 1,2 , and 3 .

however, seedling biomass was significantly and positively related to seed mass only under deep shade. For all species, the correlation between seed mass vs. seedling mass was strongest in deep shade and weaker or absent at higher light levels. Across species, the correlation coefficients of seed mass vs. seedling mass tended to increase with a decrease in light availability (Fig. 2).

Causal model connecting the three hypotheses-In the Material and Methods, we concluded in Eq. 6 that $\ln ($ seedling biomass $)=\left(a_{1}+a_{2} \times T\right)+\left(b_{1}+b_{2} \times T\right) \times \ln ($ seed mass $)$, where $a_{1}$ and $b_{1}$ are the coefficients for the reserve-effect hypothesis [ln(used reserves) vs. $\ln \left(\right.$ seed mass)], and $a_{2}$ and $b_{2}$ are the coefficients for the metabolic-effect hypothesis [RGR vs. $\ln$ (seed mass)], which is similar to Eq. $3: \ln$ (seedling biomass $)=a_{3}+b_{3} \times \ln ($ seed mass $)$, where $a_{3}=\left(a_{1}+a_{2} \times T\right)$ and $b_{3}=\left(b_{1}+b_{2} \times T\right)$.

We can estimate the slope of seed mass vs. seedling mass ( $b_{3}$; Eqs. 3 and 6) if we know $b_{1}, b_{2}$, and the time of growth $(T)$, in our case $50 \mathrm{~d}$. We made different simulations using both possible and observed values of the slopes $b_{1}$ and $b_{2}$ and as reference values.

For the reserve effect, three main results are possible: slope $>1$ (case a in Fig. 3A; Q. ilex and Q. pyrenaica in Fig. 1A), slope $=1$ (case b in Fig. 3A; Q. canariensis in Fig. 1A), and slope $<1$ (case c in Fig. 3A; Q. suber in Fig. 1A). 
TABLE 2. Mean \pm SE of variables analyzed for Quercus seedlings in different light treatments: HI: high irradiance, MI: medium irradiance, and LI: low irradiance. Specific leaf area (SLA) was calculated as the quotient between leaf area and leaf dry mass. Leaf area ratio (LAR) was calculated as the total area of leaves divided by the total seedling dry mass. The seedling biomass allocation-root mass fraction (RMF), stem mass fraction (SMF), and leaf mass fraction (LMF) — was calculated as the dry mass of root, stem, and leaves, respectively, divided by the total seedling dry mass. For the other variables, see Material and Methods. RGR, relative growth rate.

\begin{tabular}{|c|c|c|c|c|c|c|c|c|c|c|c|c|}
\hline Species & Light & $N$ & $\begin{array}{l}\text { Initial seed } \\
\text { dry mass (g) }\end{array}$ & $\begin{array}{l}\text { Used reserve } \\
\text { (g) }\end{array}$ & $\begin{array}{l}\text { Remaining } \\
\text { reserve (\%) }\end{array}$ & $\begin{array}{l}\text { Seedling dry } \\
\text { mass (g) }\end{array}$ & $\begin{array}{c}\mathrm{RGR} \\
\left(\mathrm{mg} \cdot \mathrm{g}^{-1} \cdot \mathrm{day}^{-1}\right)\end{array}$ & $\operatorname{SLA}\left(\mathrm{m}^{2} \cdot \mathrm{kg}^{-1}\right)$ & $\operatorname{LAR}\left(\mathrm{m}^{2} \cdot \mathrm{kg}^{-1}\right)$ & $\operatorname{RMF}(\mathrm{g} / \mathrm{g})$ & $\operatorname{SMF}(g / g)$ & $\operatorname{LMF}(\mathrm{g} / \mathrm{g})$ \\
\hline \multirow[t]{2}{*}{ Q. suber } & $\mathrm{HI}$ & 16 & $3.12 \pm 0.20$ & $1.96 \pm 0.1$ & $35.9 \pm 2.4$ & $1.2 \pm 0.07$ & $-10.3 \pm 1.0$ & $19.27 \pm 0.59$ & $4.98 \pm 0.28$ & $0.64 \pm 0.01$ & $0.10 \pm 0.0$ & $0.26 \pm 0.01$ \\
\hline & MI & 16 & $3.06 \pm 0.19$ & $1.97 \pm 0.1$ & $34.0 \pm 2.6$ & $1.08 \pm 0.05$ & $-12.3 \pm 1.3$ & $23.17 \pm 0.71$ & $5.17 \pm 0.29$ & $0.67 \pm 0.02$ & $0.10 \pm 0.0$ & $0.23 \pm 0.01$ \\
\hline \multirow{3}{*}{$\begin{array}{l}\text { Q. ilex subsp. } \\
\text { ballota }\end{array}$} & $\mathrm{HI}$ & 16 & $1.36 \pm 0.11$ & $0.90 \pm 0.07$ & $34.2 \pm 2.3$ & $0.66 \pm 0.05$ & $-4.6 \pm 1.9$ & $11.72 \pm 0.45$ & $3.33 \pm 0.18$ & $0.59 \pm 0.01$ & $0.13 \pm 0.01$ & $0.29 \pm 0.02$ \\
\hline & MI & 16 & $1.36 \pm 0.11$ & $0.90 \pm 0.07$ & $32.8 \pm 2.2$ & $0.60 \pm 0.05$ & $-7.6 \pm 0.8$ & $12.99 \pm 0.65$ & $3.86 \pm 0.29$ & $0.57 \pm 0.02$ & $0.13 \pm 0.01$ & $0.3 \pm 0.02$ \\
\hline & LI & 16 & $1.32 \pm 0.16$ & $0.92 \pm 0.11$ & $29.1 \pm 2.3$ & $0.54 \pm 0.05$ & $-8.4 \pm 1.1$ & $17.18 \pm 0.78$ & $3.84 \pm 0.33$ & $0.61 \pm 0.02$ & $0.16 \pm 0.02$ & $0.23 \pm 0.02$ \\
\hline Q. canariensis & $\mathrm{HI}$ & 17 & $1.43 \pm 0.10$ & $1.02 \pm 0.07$ & $27.8 \pm 1.9$ & $0.51 \pm 0.08$ & $-18.1 \pm 3.6$ & $20.44 \pm 1.45$ & $6.59 \pm 0.61$ & $0.56 \pm 0.02$ & $0.12 \pm 0.01$ & $0.32 \pm 0.02$ \\
\hline \multirow[t]{3}{*}{$Q$. pyrenaica } & $\mathrm{HI}$ & 16 & $2.18 \pm 0.22$ & $1.28 \pm 0.12$ & $40.3 \pm 1.5$ & $1.75 \pm 0.09$ & $7.1 \pm 1.9$ & $18.36 \pm 0.31$ & $3.87 \pm 0.26$ & $0.72 \pm 0.02$ & $0.07 \pm 0.01$ & $0.21 \pm 0.01$ \\
\hline & MI & 16 & $3.16 \pm 0.29$ & $1.84 \pm 0.17$ & $41.3 \pm 1.9$ & $1.71 \pm 0.12$ & $-0.8 \pm 1.8$ & $23.71 \pm 1.28$ & $3.63 \pm 0.31$ & $0.77 \pm 0.02$ & $0.07 \pm 0.01$ & $0.16 \pm 0.01$ \\
\hline & LI & 16 & $3.58 \pm 0.29$ & $1.95 \pm 0.17$ & $45.3 \pm 2.1$ & $1.49 \pm 0.12$ & $-5.2 \pm 1.2$ & $29.78 \pm 0.77$ & $2.21 \pm 0.32$ & $0.83 \pm 0.02$ & $0.1 \pm 0.01$ & $0.07 \pm 0.01$ \\
\hline
\end{tabular}

For the metabolic effect, three main results are also possible: slope $=0$ (case 1 in Fig. 3B; Q. suber in Fig. 1B), slope $<0$ (case 2 in Fig. 3B; Q. ilex and $Q$. pyrenaica in Fig. $1 \mathrm{~B}$ ), and slope $>0$ (case 3 in Fig. 3B; no example in our study followed this pattern). The combinations of these possible results generate nine simulations of $\ln$ seedling biomass $-\ln$ seed mass (the seedling-size effect) (Fig. 3C). The slopes of the linear regression $\ln$ seedling mass $-\ln$ seed mass $\left(b_{3}\right)$ are the same as those calculated as $b_{1}+b_{2} \times T$ from the $\ln$ used reserve $-\ln$ seed mass (slope $b_{1}$ ) and RGR $-\ln$ seed mass (slope $b_{2}$ ) linear regressions. We can see that in eight of the nine combinations, seedling mass is positively related to seed mass, and therefore the hypothesis of seedlingsize effect is accepted. Only in one case (case c-2 in Fig. 3C) was the resulting relationship of seedling mass vs. seed mass lost [where the slope of used reserve vs. seed mass was less than one (case c in Fig. 3A), and the slope of RGR vs.seed mass was negative (case 2 in Fig. 3B)]. Therefore, we can conclude that larger seeds generally produce larger seedlings, and only in some cases is seed mass unrelated to seedling biomass.

One way to use our data to check the connection between the hypotheses is to estimate the slopes of ln seedling biomass - ln seed mass (as $\left.b_{1}+b_{2} \times T\right)$ and compare them with the observed slopes of these relationships $\left(b_{3}\right)$. We have only four cases with significant correlations in both $\ln$ used reserve - ln seed mass and RGR - In seed mass $(Q$. ilex $\mathrm{HI}, Q$. ilex LI, $Q$. pyrenaica MI, and $Q$. pyrenaica LI; Fig. 1). Consequently, the connection of the three hypotheses can be evaluated only with these four cases because of the significant and linear relationship between $X$ and $Y$. If the slopes of $\ln$ seedling - $\ln$ seed mass are calculated using the slope $b_{1}$ (Eq. 1) and $b_{2}$ (Eq. 2) and assuming a $T$ of $50 \mathrm{~d}$, we can estimate the slope of ln seedling - In seed mass, and this slope can be compared to the slope of the regression line drawn from the observed data (ln seed mass and $\ln$ seedling biomass). The estimated and observed slopes of ln seedling - ln seed mass were strongly correlated (Pearson correlation, $r=0.99, P<0.01$ ), which can be considered as a proof of the connection of the three hypotheses.

\section{DISCUSSION}

While seedlings establish, their mortality rates tend to be very high because of many hazards, and consequently natural selection may operate strongly during this life stage (Leishman et al., 2000). In general, larger-seeded species tend to perform better under a diversity of adverse establishment conditions. What are the mechanisms translating a larger seed mass in a successful seedling under hazardous conditions? In this study, we evaluated three hypotheses concerning the influence of initial seed mass on seed reserve use and seedling traits within four congeners growing under contrasting light conditions. We tested whether larger seeds retain more reserves than do smaller seeds (the reserve effect), whether seed mass is negatively related to RGR (the metabolic effect), and whether larger seeds result in a larger seedling mass (the seedling-size effect). Overall, seed mass had highly significant effects on seed and seedlings traits, but these effects depended on species and light conditions.

Reserve effect-The reserve hypothesis postulates that (1) larger seeds retain a larger proportion of their reserves and (2) the slope of the seedling biomass vs. seed mass is significantly greater than the slope of the used reserve vs. seed mass (Green and Juniper, 2004a). In this way, the reserves can be mobilized later to support the seedlings during periods of carbon deficit, for example when growing in deep shade. Only one of four species tested ( $Q$. suber in full light) met condition 1 of this hypothesis, with a larger proportion of reserves retained in large seeds. Notably, this was the largest seeded species, the reserves of which could be mobilized for future hazards, especially at high irradiance levels. However, condition 2 was not satisfied by this species. Therefore, no reserve effect was evident in any Quercus species in our experiment. Similarly, Green and Juniper (2004a) found that within species, the seedreserve effect was not very common (only seven of 22 Australian rainforest species tested had a seed-reserve effect).

All Quercus species retained a large part (between 22 to $45 \%$; Table 2) of their initial seed reserves by the end of the experiment. The question is whether those reserves can be 
mobilized later in case of stress or disturbance such as herbivore damage. Greenhouse and field experiments have shown that Quercus seedlings can indeed resprout after stem removal (Harmer, 1999; Kullberg and Wellander, 2003; Kabeya and Sakai, 2005), but the ability to resprout is independent of seed size (Erniwati, 2006), probably because the remaining reserves are more than sufficient to resprout once. Perhaps repeated clipping would have revealed a seed-size effect.

Metabolic effect-The metabolic hypothesis predicts a negative relationship between seedling relative growth rate (RGR) and seed size (Shipley and Peters, 1990; Marañón and Grubb, 1993). If plants have a slower RGR and a slower metabolic rate, they would use seed resources more slowly and be able to rely on seed reserves longer (Green and Juniper, 2004a). This hypothesis was confirmed for only two species (Q. ilex and $Q$. pyrenaica). For these species, the relationship between RGR and seed strengthened with an increase in irradiance. Similarly, Poorter and Rose (2005) found in a between-species study that the relationship between RGR and seed size had a greater slope under high-light conditions, when the small-seeded (pioneer) species can realize their full growth potential, whereas the large-seeded (shade-tolerant) species have a low inherent growth rate.

Seedling-size effect-The seedling-size hypothesis proposes that larger seeds produce larger seedlings, which are more robust and better able to escape size-dependent mortality. In our experiment, such a relationship was found for species in at least one light level, as reported elsewhere (McComb, 1934; Bonfil, 1998; Ke and Werger, 1999; Rey et al., 2004; Baraloto et al., 2005). However, other studies attribute this positive relationship within species to other traits indirectly associated with seed size, such as genetic variability of the maternal plant (Castro, 1999). In our study, light availability was another source of variation: $Q$. ilex and $Q$. pyrenaica met the seedlingsize hypothesis in all light treatments, whereas a positive relationship between seedling mass and seed mass was found only in deep shade for the other two species. Moreover, all species had a strong correlation between seed mass and seedling biomass in deep shade, but this relationship weakened or disappeared in higher light (Fig. 2). Strong correlations between seed mass and seedling biomass can be expected in deep shade (Fig. 2), where seedlings have low photosynthetic rates (Quero et al., 2006) and depend mostly on seed reserves for their growth. Under intermediate and optimal light conditions, seedling growth becomes more autotrophic, and hence, genotypic differences become more important determinants of intraspecific variation in seedling growth and mass. Across species, this pattern is consistent with other studies that demonstrate better performance of larger-seeded species (as these Quercus are) in deep shade (Saverimuttu and Westoby, 1996; Poorter and Rose, 2005).

A causal model connecting the three hypotheses-The three hypotheses have been postulated as possible mechanisms explaining how seedlings tolerate different hazards (Westoby et al., 1996), but up to now there has not been any attempt to connect them. Here we present a causal model that connects the three hypotheses and helps us evaluate how seed size affects the seedling biomass of these species.

The principal result of the proposed causal model is that there are strong possibilities of finding a seedling-size effect, as found in many studies (Bonfil, 1998; Castro, 1999; Ke and Werger, 1999; Rey et al., 2004; Baraloto et al., 2005). This model gives the mathematical explanation of this general result. The relationship between seedling biomass and seed mass depends on the slope of used reserve against seed mass, the slope of RGR against seed mass, and on the duration of the growth period. Although a seedling-size effect is demonstrated by most of our modeled cases, the effect is weaker or disappear when RGR is strongly and negatively related to seed mass and when the proportion of used reserves decreases with seed mass. For some species in our study, RGR was strongly and negatively related with seed mass (e.g., $Q$. pyrenaica in $\mathrm{HI}$ and MI) and, according to our model, these cases lacked any seedling-size effect.

Our model also predicts that the time of growth can influence seed-seedling relationships, this depending also on the relationship of RGR with seed mass (the slope $b_{2}$ ). According to our model, the slope of seed mass vs. seedling mass $\left(b_{3}\right)$ is equal to $b_{1}+b_{2} \times T$. If $b_{2}$ is zero, the time of growth will have little effect on $b_{3}$, but if $b_{2}$ is negative, increasing the time of growth will reduce the value of $b_{3}$. The literature generally shows that the slope $b_{2}$ (the slope of RGR vs. seed mass) is zero or negative (our current study and Poorter and Rose, 2005), indicating that the seedling-seed effect would disappear with time. Poorter and Rose (2005) reported that the strength of the correlation between growth parameters and seed mass declines over time and disappears after 1-4 yr. Also, Castro (1999) found that seed mass of Pinus sylvestris L. did not affect seedling performance after one growing season.

Ecological implications-How can we translate these experimental results to the field? Mediterranean Quercus forests generally experience substantial environmental perturbation including drought and fire (Aschman, 1973; Ojeda, 2001) and substantial herbivory on acorns and seedlings (Gómez et al., 2003; Zamora et al., 2004). In this scenario, large seeds benefit Quercus seedlings in four ways: they (1) increase emergence and seedling establishment in soils with low fertility or other adverse characteristics (Puerta-Piñero et al., 2006); (2) produce larger seedlings with longer roots that increase the chances of surviving summer drought (Metcalfe and Grubb, 1997; Lloret et al., 1999); (3) enable resprouting after herbivory because the seedling retains a substantial part of the initial seed reserves (Green and Juniper, 2004b); and (4) facilitate seedling establishment in shady environments, where acorns are frequently dispersed by jays and rodents (Bosema, 1979; Gómez, 2003).

This study provides evidence for two of the three hypotheses that explain how seed size affects seedling performance; the metabolic effect and the seedling-size effect were supported. According to the causal model, larger seeds usually produce larger seedlings. These hypotheses have been confirmed within species, suggesting that functional relationships underlie the observed patterns. The strongest correlations between seed size and seedling biomass were found in the shade, indicating that seedlings in low light depend more on their seed reserves.

\section{LITERATURE CITED}

Aizen, M. A., And W. A. Patterson III. 1990. Acorn size and geographical range in the North American oaks. Journal of Biogeography 17: 327332. 
Amaral, J. 1990. Quercus. In S. Castroviejo, M. Laínz, G. LópezGonzález, P. Montserrat, F. Muñoz-Garmendia, J. Paiva, and L. Villar [eds.], Flora ibérica, vol. II, 15-36. CSIC, Real Jardín Botánico, Madrid, Spain.

Aschmann, H. 1973. Diversity and peculiarity of Mediterranean ecosystems. In F. diCastri and H. A. Mooney [eds.], Mediterranean type ecosystems origin and structure, 11-19. Springer-Verlag, New York, New York, USA.

Baraloto, C., P. M. Forget, and D. E. Goldberg. 2005. Seed mass, seedling size and neotropical tree seedling establishment. Journal of Ecology 53: 1156-1166.

Bond, W. J., M. Honing, AND K. E. Maze. 1999. Seed size and seedling emergence: an allometric relationship and some ecological implications. Oecologia 120: 132-136.

BonfiL, C. 1998. The effects of seed size, cotyledon reserves, and herbivory on seedling survival and growth in Quercus rugosa and $Q$. laurina (Fagaceae). American Journal of Botany 85: 79-87.

Bossema, I. 1979. Jays and oaks: an eco-ethological study of a symbiosis. Behaviour 70: 1-117.

CASTRO, J. 1999. Seed mass versus seedling performance in Scots pine: a maternally dependent trait. New Phytologist 144: 153-161.

Cornelissen, J. H. C., P. Castro-Díez, and R. Hunt. 1996. Seedling growth, allocation and leaf attributes in a wide range of woody plant species and types. Journal of Ecology 84: 755-765.

ERNIWATI. 2006. The role of seed size in the re-sprouting ability of oak seedlings. Do larger seeds of $Q$. robur and $Q$. petraea have an advantage by saving more resource for re-sprouting? Master's thesis, Wageningen University, Wageningen, Netherlands.

Falster, D. S., D. I. Warton, AND I. J. WRight. 2003. (S)MATR: standardised major axis tests and routines, version 1.0. Website http:// www.bio.mq.edu.au/ecology/SMATR [accessed 20-May-07].

Foster, S. A. 1986. On the adaptive value of large seeds for tropical moist forest trees-a review and synthesis. Botanical Review 52: 260-299.

García-Cebrián, F., J. Esteso-Martínez, and E. Gil-Pelegrín. 2003. Influence of cotyledon removal on early seedling growth in Quercus robur L. Annals of Forest Science 60: 69-73.

Gómez, J. M. 2003. Spatial patterns in long-distance dispersal of Quercus ilex acorns by jays in a heterogeneous landscape. Ecography 23: 573584.

Gómez, J. M., D. García, and R. Zamora. 2003. Impact of vertebrate acorn- and seedling-predators on a Mediterranean Quercus pyrenaica forest. Forest Ecology and Management 180: 125-134.

Gómez-Aparicio, L., F. Valladares, and R. Zamora. 2006. Differential light responses of Mediterranean tree saplings: linking ecophysiology with regeneration niche in four co-occurring species. Tree Physiology 26: 947-958.

Green, P. T., AND P. A. JuniPer. 2004a. Seed-seedling allometry in tropical rain forest trees: seed mass-related patterns of resource allocation and the 'reserve effect'. Journal of Ecology 92: 397-408.

GreEN, P. T., AND P. A. JUNIPER. 2004b. Seed mass, seedling herbivory and the reserve effect in tropical rainforest seedlings. Functional Ecology 18: 539-547.

HARMER, R. 1999. Survival and new shoot production by artificially browsed seedlings of ash, beech, oak and sycamore grown under different levels of shade. Forest Ecology and Management 116: 3950 .

HaRms, K. E., AND J. W. DAluing. 1997. Damage and herbivory tolerance through resprouting as an advantage of large seed size in tropical trees and lianas. Journal of Tropical Ecology 13: 617-621.

Jurado, E., AND M. Westoby. 1992. Seedling growth in relation to seed size among species of arid Australia. Journal of Ecology 80: 407416.

KABEYA, D., AND S. SAKAI. 2005. The relative importance of carbohydrate and nitrogen for the resprouting ability of Quercus crispula seedlings. Annals of Botany 96: 479-488.

Ke, G., And M. J. A. Werger. 1999. Different responses to shade of evergreen and deciduous oak seedlings and the effect of acorn size. Acta Oecologia 20: 579-586.

Kitajima, K. 1996. Cotyledon functional morphology, patterns of seed reserve utilization and regeneration niches of tropical tree seedlings. In M. D. Swaine [ed.], The ecology of tropical forest tree seedlings, 193-210. Parthenon, Carnforth, UK.

Kullberg, Y., and N. T. Wellander. 2003. Effect of simulated winter browsing and drought on growth of Quercus robur L. seedlings during establishment. Forest Ecology and Management 173: 125133.

LEgEndRe, P. 2000. Model II regression-User's guide. Département de Sciences Biologiques. Université de Montréal, Montreal, Canada. Website http://www.fas.umontreal.ca/biol/legendre/ [accessed 14Aug-07].

Leishman, M. R., and M. Westoby. 1994. The role of large seed size in shaded conditions: effect of seed size. Functional Ecology 8: 205214.

Leishman, M. R., I. J. Wright, A. T. Moles, and M. Westoby. 2000. The evolutionary ecology of seed size. In M. Fenner [ed.], Seeds: ecology of regeneration in plant communities, 31-57. CAB International, Wallingford, UK.

LeIva, M. J., AND R. FERnÁNDEZ-AlÉs. 1998. Variability in seedling water status during drought within a Quercus ilex subsp. ballota population, and its relation to seedling morphology. Forest Ecology and Management 111: 147-156.

Lloret, F., C. Casanovas, and J. Peñuelas. 1999. Seedling survival of Mediterranean shrubland species in relation to root : shoot ratio, seed size and water and nitrogen use. Functional Ecology 13: 210-216.

Marañón, T., AND P. GrubB. 1993. Physiological basis and ecological significance of the seed size and relative growth rate relationship in Mediterranean annuals. Functional Ecology 7: 591-599.

Marañón, T., R. Zamora, R. Villar, M. A. Zavala, J. L. Quero, I. PérezRamos, I. Mendoza, and J. Castro. 2004a. Regeneration of tree species and restoration under contrasted Mediterranean habitats: field and glasshouse experiments. International Journal of Ecology and Environmental Sciences 30: 187-196.

МсСомв, А. L. 1934. The relation between acorn weight and the development of one year chestnut oak seedlings. Journal of Forestry 32: 479-484

Metcalfe, D. J., and P. J. GrubB. 1997. The response to shade of seedling of very small-seeded tree and shrub species from tropical rain forest in Singapore. Functional Ecology 11: 215-221.

Milberg, P., L. Andersson, AND K. Thompson. 2000. Large-seeded species are less dependent on light for germination than small-seeded ones. Seed Science Research 10: 99-104.

OJEDA, F. 2001. El fuego como factor clave en la evolución de las plantas mediterráneas. In R. Zamora and F. I. Pugnaire [eds.], 351-372 Ecosistemas mediterráneos, análisis funcional, vol. 32, CSIC-AEET, Granada, Spain.

Pearson, T. R. H., D. F. R. P. Burslem, C. E. Mullis, and J. W. Dalling. 2002. Germination ecology of neotropical pioneers: interacting effects of environmental conditions and seed size. Ecology 83: 2798-2807.

PoORTER, L., AND Y. HAYASHIDA-OLIVER. 2000. Effects of seasonal drought on gap and understorey seedlings in a Bolivian moist forest. Journal of Tropical Ecology 16: 481-498.

Poorter, L., AND S. A. Rose. 2005. Light-dependent changes in the relationship between seed mass and seedling traits: a meta-analysis for rain forest tree species. Oecologia 142: 378-387.

Puerta-Piñero, C., J. M. Gómez, and R. Zamora. 2006. Species-specific effects on topsoil development affect Quercus ilex seedling performance. Acta Oecologia 29: 65-71.

Quero, J. L., R. Villar, and T. Marañón. 2003. Crecimiento y supervivencia de Quercus pyrenaica Willd. y Quercus suber L. en diferentes micrositios: un experimento de campo en dos zonas contrastadas climáticamente. In Actas del VII Congreso Nacional de la Asociación Española de Ecología Terrestre, 600-613. Soft Congress S. L., Barcelona, Spain.

Quero, J. L., R. Villar, T. Marañón, AND R. Zamora. 2006. Interactions of drought and shade effects on four Mediterranean Quercus species: physiological and structural leaf responses. New Phytologist 170: 819-834.

Rey, P. J., J. M. Alcántara, F. Valera, A. M. Sánchez-Lafuente, J. L. 
Garrido, J. M. Ramírez, and A. J. Manzaneda. 2004. Seedling establishment in Olea europaea: seed size and microhabitat affect growth and survival. Ecoscience 11: 310-320.

Rose, S. A. 2000. Seeds, seedlings and gaps-size matters. A study in the tropical rain forest of Guyana. Ph.D. dissertation, Utrecht University, Tropenbos-Guyana series 9, Ipskamp, Enschede, Netherlands.

SACK, L. 2004. Responses of temperate woody seedlings to shade and drought: do trade-offs limit potential niche differentiation? Oikos 107: $110-127$.

Saverimuttu, T., And M. Westoby. 1996. Seedling longevity under deep shade in relation to seed size. Journal of Ecology 84: 681-689.

Serwa, K. 2000. Effects of seed size and emergence time on tree seedling establishment: importance of developmental constraints. Oecologia 123: 208-215.

Shipley, B., AND R. H. Peters. 1990. The allometry of seed weight and seedling relative growth rate. Functional Ecology 4: 523-529.

Steege, H. T., C. Bokdam, M. Boland, J. Dobbelsteen, and I. Verburg. 1994. The effects of man-made gaps on germination, early survival, and morphology, of Chlorocardium rodiei seedlings in Guyana. Journal of Tropical Ecology 10: 245-260.

Urbieta, I. R., M. A. Zavala, and T. Marañón. 2004. Distribución y abundancia de alcornoque Quercus suber L. y quejigo Quercus canariensis Willd. y su relación con factores ambientales en la provincia de Cádiz. Revista de la Sociedad Gaditana de Historia Natural 4: 183-189.

VAlLADARes, F. 2001. Light and plant evolution. Scientific American 303: 73-79.
Westoby, M., D. S. Falster, A. T. Moles, P. A. Vesk, and I. J. Wright. 2002. Plant ecological strategies: some leading dimensions of variation between species. Annual Review of Ecology and Systematics 33: $125-159$.

Westoby, M., M. Leishman, AND J. LoRd. 1996. Comparative ecology of seed size and dispersal. Philosophical Transactions of the Royal Society of London, B, Biological Sciences 351: 1309-1318.

Wright, I. J., H. T. Clifford, R. Kidson, M. L. Reed, B. L. Rice, And M. Westoвy. 2000 A survey of seed and seedling characteristics in 1744 Australian dicotyledon species: cross-species trait correlations and correlated trait-shifts within evolutionary lineages. Biology Journal of the Linnean Society 69: 521-547.

Wright, I. J., AND M. Westoby. 1999. Differences in seedling growth behaviour among species: trait correlations across species, and trait shifts along nutrient compared with rainfall gradients. Journal of Ecology 87: 85-97.

Zamora, R., P. García-Fayos, and L. Gómez-Aparicio. 2004. Las interacciones planta-planta y planta-animal en el contexto de la sucesión ecológica. In F. Valladares [ed.], Ecología del bosque mediterráneo en un mundo cambiante, 371-393. Ministerio de Medio Ambiente, Madrid, Spain.

Zanne, A. E., C. A. Chapman, and K. Kitajima. 2005. Evolutionary and ecological correlates of early seedling morphology in east African trees and shrubs. American Journal of Botany 92: 972-978.

ZAR, J. H. 1984. Biostatistical analysis. Prentice Hall, Englewood Cliffs, New Jersey, USA. 